\title{
High-performance active power filter implementation based on predictive current control
}

\author{
Bachar Rahima, Golea Amar, Benchouia Mohamed Toufik, Chebaani Mohamed \\ L.G.E.B Laboratory, Department of Electrical Engineering, Biskra University, Algeria
}

\begin{tabular}{|c|c|}
\hline Article Info & ABSTRACT \\
\hline Article history: & This paper presents the use of the predictive strategy concept to improve the \\
\hline Received Feb 3, 2018 & $\begin{array}{l}\text { Active Power Filter (APF) performance, by compensation of the reactive } \\
\text { power and elimination of the harmonic currents generated by non-linear }\end{array}$ \\
\hline Revised Oct 26, 2018 & loads. Predictive control is generating considerable interest when it comes to \\
\hline Accepted Dec 13, 2018 & $\begin{array}{l}\text { implementing current control strategies in active power filter. The proposed } \\
\text { strategy provides a simple controller incorporating Phase Locked Loop }\end{array}$ \\
\hline \multirow{6}{*}{$\begin{array}{l}\text { Keywords: } \\
\text { Active power filter (APF) } \\
\text { Multi variable filter (MVF) } \\
\text { Phase locked loop (PLL) } \\
\text { DSPACE } 1104 \\
\text { Predictive controller }\end{array}$} & $\begin{array}{l}\text { (PLL) independency. The prediction is evaluated using a cost function that } \\
\text { quantifies the desired system behavior. The cost function used in this work }\end{array}$ \\
\hline & evaluates the filtered error of the currents. This strategy minimized the \\
\hline & $\begin{array}{l}\text { number of sensors, ease of practical implementation and reduced system size } \\
\text { and cost. The effectiveness of the proposed controller is confirmed through }\end{array}$ \\
\hline & simulation and experimental validation using a hardware prototype based on \\
\hline & dSPACE-1104 \\
\hline & $\begin{array}{r}\text { Copyright (C) } 2019 \text { Institute of Advanced Engineering and Science. } \\
\text { All rights reserved. }\end{array}$ \\
\hline
\end{tabular}

\section{Corresponding Author:}

Bachar Rahima,

L.G.E.B.Laboratory,

Department of Electrical Engineering,

Biskra University, Algeria.

Email: rahima_3001@yahoo.com

\section{INTRODUCTION}

Recently the power electronics based nonlinear loads are increased tremendously in the distribution network. These include, switched mode power supplies, variable speed drives and uninterrupted power supplies. These nonlinear loads create harmonics or current distortion problem in the supply side of the distribution system. The harmonic currents induce malfunctions of sensitive equipments, over voltage by resonance and harmonic voltage drop across the network impedance; these significantly deteriorate the power quality in the distribution system. So, it is necessary to develop techniques to reduce all the harmonics as it is recommended in the IEEE 519-1992. Traditional solution (passive filters) is associated with certain limitation, like fixed compensation, resonance problem and bulky in nature. In order to overcome the above mentioned limitations, since its introduction some twenty years ago, the Active Power Filters (APF) have presented a good solution. Basic principle of the APF is proposed by Gyugyi and Strycula in the year 1976 [1]-[3].

Generally, the APF acts as a harmonic current source, which injects an anti-phase but equal magnitude of the harmonic and reactive load current. As a result, components of harmonic currents contained in the load current are cancelled and the source current remains sinusoidal and in phase with the respective phase voltage. Figure 1 shows the basic concept and the principle of the APF compensation [4]-[6]. 


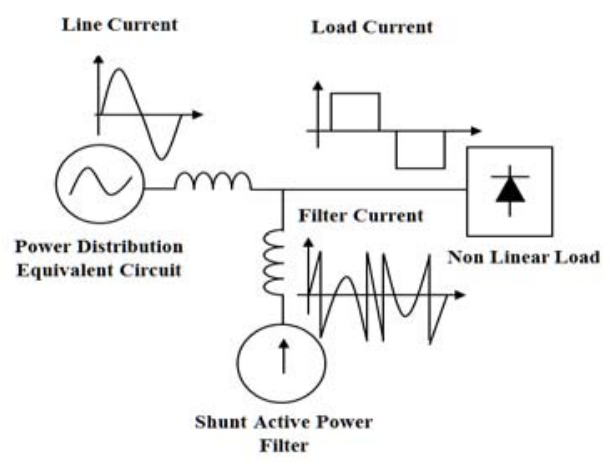

Figure 1. Shunt active power filter operating principle

The PI controller which was used for controlling the APF requires precise linear mathematical models, which are difficult to obtain. So, satisfactory performance under parameter variations and load disturbances can not be obtained.With the development of powerful and fast microprocessors, several techniques addressed to control these kinds of power converters have been the subject of numerous researches in recent years, such as Sliding Mode Control (SMC) [6], optimal control and Model Predictive Control (MPC) [7]-[14]. Currently, and thanks to the potential of digital signal processors (DSPs), the MPC is a promising control method and has several benefits such as fast tracking response, a high control bandwidth and a very easiest way to include system nonlinearities and constraints [15].

Two different control strategies regarding the MPC algorithms can be adopted: Continuous Control Set-Model Predictive Control (CCS-MPC) and Finite Control Set- Model Predictive Control (FCS-MPC) [9] [16]. The former is based on the prediction of the sate variables according to a discrete model of the converter. These predictions are evaluated in a cost function over a prediction horizon in order to obtain a sequence of the future control actions. Then, only the first value of this sequence is considered and the algorithm is computed in each sampling period. This approach has several advantages such as an improvement of the THD and the fixed switching frequency. However, a high amount of calculations are needed in order to solve the cost function which makes this option a more complex solution. In the latter, the optimization problem is reduced to a finite number of switching states. Here, the cost function is calculated for every switching state, each one related to a specific voltage vector. The switching state that minimizes the error between the current and its reference is then applied to the converter. In this way, the cost function is evaluated in a finite number of times each sampling period [10], [17], [18].

In this paper a predictive current control technique for a shunt APF is presented. Actual values of load currents are measured and injected in the predictive model to generate predictions of future current, one for each voltage vector. These predictions are evaluated with a quality function and the vector that minimizes this function is applied during the next sampling interval. A capacitor voltage control technique previously used as a harmonic current extraction technique. Predictive current control based on the supply current is proposed in Figure 2.

The proposed work is developed in the following sections. Firstly, the generation of the reference current is presented. Secondly, the modelisation of the grid-connected inverter is developed. Finally, Simulation results using matlab/ Simulink and experimental results around Dspace-1104 are presented.

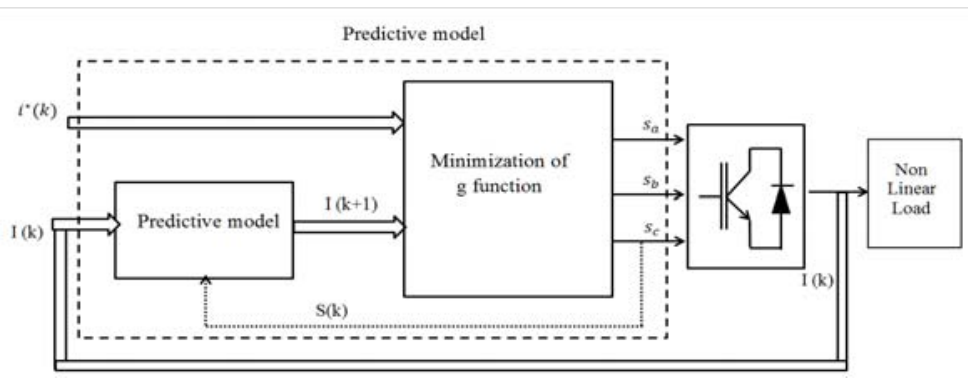

Figure 2. Predictive current control block diagram

Int J Pow Elec \& Dri Syst, Vol. 10, No. 1, March 2019: 277 - 287 


\section{REFERENCE CURRENT GENERATION}

Among the presented methods for identifying harmonic components of the load current, a simplified and applicable method with high performance is presented in [19]-[22]. The important question of the APF is how to calculate the appropriate compensation current, which will be detailed in the next section.

The block diagram of the proposed harmonic extraction method is performed using the capacitor voltage control shown in Figure 3. The main purpose of the suggested approach is to regulate the power flow of the whole system as well as to compensate harmonic and reactive currents, using the Predictive Current Control (PCC) in all operation modes. It consists of two parts; the first one is the reference current generation and the second one is the regulation of the capacitor voltage, using a PI controller. The output is proportional to the instantaneous changes in power balance. Multiplying this output by the per unit voltages of the common coupling point (output of the PLL). Then, by subtracting source currents from filter currents, the reference filter currents will be extracted. Figure 3 shows the proposed block diagram.

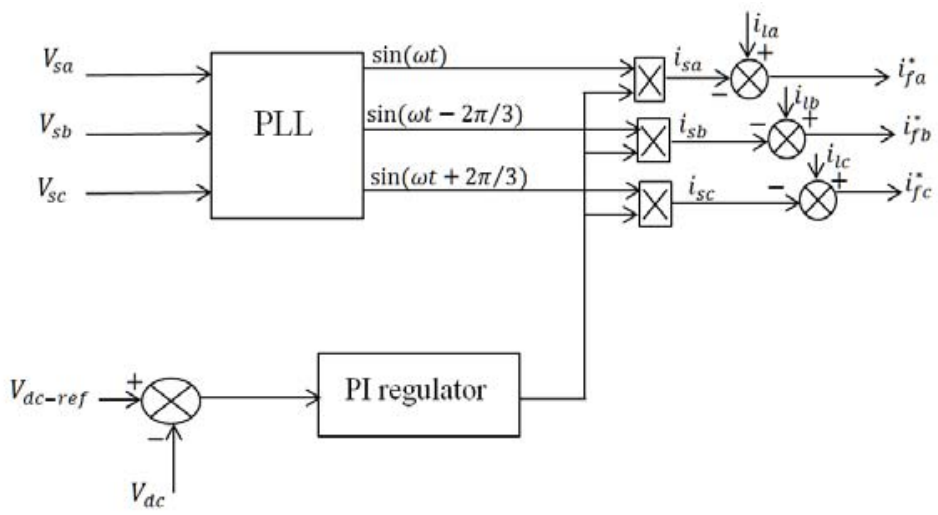

Figure 3. Capacitor voltage control

\subsection{PI-controller}

Figure 3 shows the block diagram of the PI control scheme for the active power filter. The DC-bus voltage is sensed and compared with a reference voltage and also calculating the error signal. The error signal is used as input for the PI controller. The PI controller estimates the magnitude of the reference current peak and controls the dc-bus voltage of the inverter. Where, $\left[k_{p}=0.2\right]$ is the proportional constant that determines the dynamic response of the DC-bus voltage and $\left[k_{i}=15\right]$ is the integration constant that determines the settling time.

\subsection{Phase Locked Loop (PLL)}

Either the measured voltages on a three-phase network $\mathrm{v}_{\mathrm{sa}}, \mathrm{v}_{\mathrm{sb}}$ and $\mathrm{v}_{\mathrm{sc}}$ subjected to a direct Concordia $\mathrm{C} 32$ transformation to work in a reference system $\alpha \beta$ two dimensions. The voltages obtained are $\mathrm{v}_{\mathrm{s} \alpha}\left(\theta_{\mathrm{d}}\right) \operatorname{andv}_{\mathrm{s} \beta}\left(\theta_{\mathrm{d}}\right)$ (with $\theta_{\mathrm{d}}$ instantaneous phase of the actual forward voltage). The rotation angle $\theta_{d}$ is obtained by integration of the estimate angular frequency $\left(w_{d}\right)$ determined by the PI controller. In order for the PLL to be closed, the estimated rotation angle $\left(\theta_{d}\right)$ must be equal to the actual angle of the forward voltage $\left(\theta_{d}\right)$, this can be achieved when the value of $\left(v_{\text {dref }}\right)$ is zero [1]. Let's the measured voltages at the connection point of the APF considered as sinusoidal and balanced, given by the following equations:

$$
\left\{\begin{array}{c}
v_{s a}=\sqrt{2} V \sin \left(\theta_{d}\right) \\
v_{s b}=\sqrt{2} V \sin \left(\theta_{d}-\frac{2 \pi}{3}\right) \\
v_{s c}=\sqrt{2} V \sin \left(\theta_{d}+\frac{2 \pi}{3}\right)
\end{array}\right.
$$

The calculation procedure after application of the transformation of Concordia and Park is given by the following relationship:

High-performance active power filter implementation based on predictive current control (Bachar Rahimap) 


$$
\left[\begin{array}{l}
v_{s d} \\
v_{s q}
\end{array}\right]=\sqrt{3} V\left[\begin{array}{c}
\sin \left(\theta_{d}-\hat{\theta}_{d}\right) \\
-\cos \left(\theta_{d}-\hat{\theta}_{d}\right)
\end{array}\right]
$$

where $\mathrm{C} 32$ is the Concordia matrix given by:

$$
C_{32}=\sqrt{\frac{2}{3}}\left[\begin{array}{ccc}
1 & -\frac{1}{2} & -\frac{1}{2} \\
0 & \frac{\sqrt{3}}{2} & -\frac{\sqrt{3}}{2}
\end{array}\right]
$$

The operator $P$ symbol the Park transformation, defined by:

$$
p\left(\hat{\theta}_{d}\right)=\left[\begin{array}{cc}
\cos \left(\hat{\theta}_{d}\right) & \sin \left(\hat{\theta}_{d}\right) \\
-\sin \left(\hat{\theta}_{d}\right) & \cos \left(\hat{\theta}_{d}\right)
\end{array}\right]
$$

The phase subjection will be achieved when $\theta_{d}=\hat{\theta}_{d}$. In this case, the actual angle of the network voltage and the estimated angle are equal. So, we can write:

$$
\left\{\begin{array}{c}
v_{s d}=0 \\
v_{s q}=-\sqrt{3} V_{d}
\end{array}\right.
$$

To search other compromise between the dynamic behavior of conventional PLL and its insensitivity to various disturbances, a new approach is to introduce a Multi Variable Filter (MVF) between two quadratic pins of the conventional version of the PLL in order to overcome these disturbances behavioral problems Figure 4. The transfer function of the MVF as shown in Figure 5 is expressed by the following expression:

$$
H(s)=\frac{v_{\alpha \beta}^{*}}{v_{\alpha \beta}}=k \frac{(s+k)+j w_{c}}{(s+k)^{2}+w_{c}^{2}}
$$

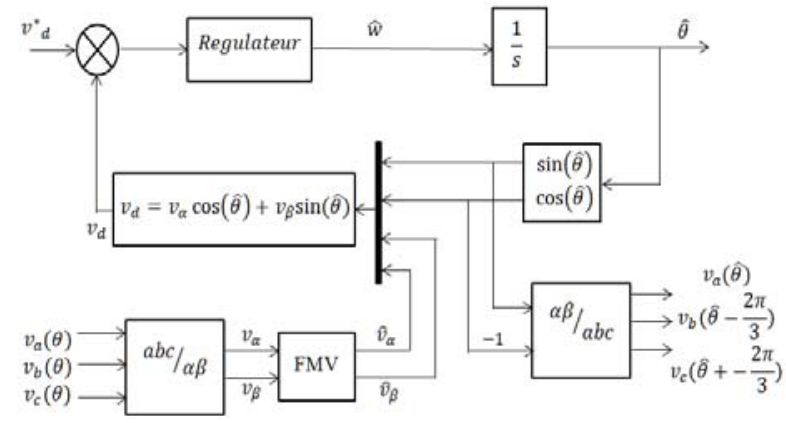

Figure 4. Structure of conventional P.L.L with MVF

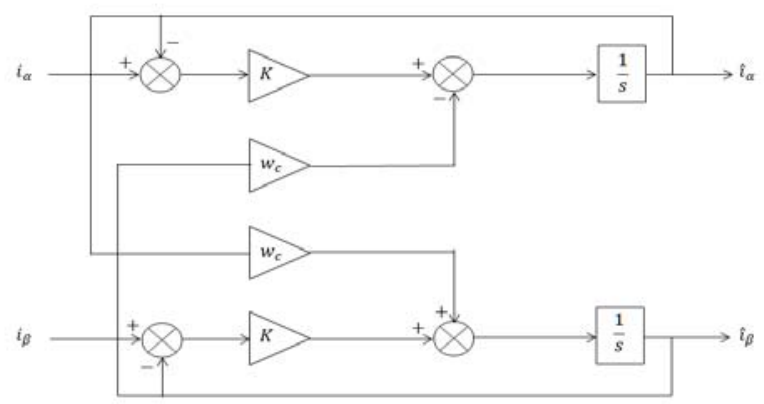

Figure 5. Schematic diagram of the PLL including a MVF 


\section{MODDELING OF A GRID-CONNECTED INVERTER WITH L-FILTER}

The three-phase shunt APF circuit as shown in Figure 6. From this circuit, the following equations for each phase-leg can be defined as follows:

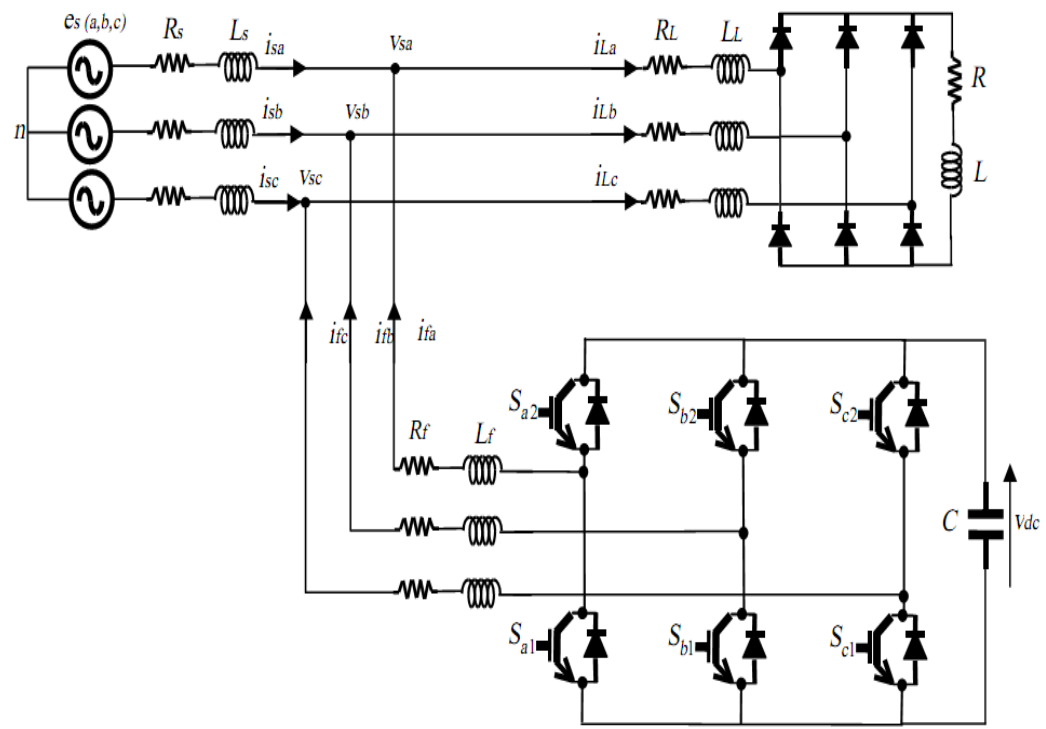

Figure 6. Shunt active power filter

Assuming the variables $S_{a}, S_{b}$ and $S_{c}$ represent the switching states of each phase, where "1" stands for the inverter output connected to the positive dc-link voltage, and " 0 " means that the inverter output is connected to the negative dc-link voltage. Switching states of the two-level three-phase inverter can be represented by $S_{j}$, with $\mathrm{j}=0, \ldots, 7$. According to output switching combinations, totally 8 voltage vectors can be generated [17], [18], [22]. The switching states of the converter are determined by the gating signal $S_{a}, S_{b}$ and $S_{c}$ as follows:

$$
\begin{gathered}
S_{a}= \begin{cases}1, & \text { if } S_{1} \text { on and } S_{4} \text { off } \\
0, & \text { if } S_{1} \text { off } \text { and } S_{4} \text { on }\end{cases} \\
S_{b}= \begin{cases}1, & \text { if } S_{2} \text { on and } S_{5} \text { off } \\
0, & \text { if } S_{2} \text { off and } S_{5} \text { on }\end{cases} \\
S_{c}= \begin{cases}1, & \text { if } S_{3} \text { on and } S_{6} \text { off } \\
0, & \text { if } S_{3} \text { off and } S_{6} \text { on }\end{cases}
\end{gathered}
$$

And can be expressed in vectorial form by

$$
S=\frac{2}{3}\left(S_{a}+a \cdot S_{b}+a^{2} \cdot S_{c}\right)
$$

Where $a=e^{j 2 \pi / 3}$

The output space voltage vectors generated by the inverter are defined by

$$
V_{f}=\frac{2}{3}\left(v_{f a}+a \cdot v_{f b}+a^{2} \cdot v_{f c}\right)
$$

The output phase voltages $v_{f a} v_{f b}$ and $v_{f c}$ can be expressed as:

$$
\left[\begin{array}{l}
v_{f a} \\
v_{f b} \\
v_{f c}
\end{array}\right]=\left[\begin{array}{l}
S_{a} \\
S_{b} \\
S_{c}
\end{array}\right] v_{d c}
$$


Then, the output voltage vector can be related to the switching state vector by;

$$
V_{f}=S \cdot v_{d c}
$$

According to the reference current direction in Figure 1, the output currents of the two-level threephase inverter can be expressed as:

$$
\left\{\begin{array}{l}
L \frac{d i_{f a}}{d t}=v_{s a}-v_{f a} \\
L \frac{d i_{f b}}{d t}=v_{s b}-v_{f b} \\
L \frac{d i_{f c}}{d t}=v_{s c}-v_{f c}
\end{array}\right.
$$

The mathematic model of the three-phase inverter in the abc reference frame needs to be transformed to the model in the stationary reference frame [22] [9] [23], using the corresponding transformation matrix (invariant amplitude transformation) given by.

$$
C_{3 / 2}=\frac{2}{3}\left[\begin{array}{ccc}
1 & -1 / 2 & -1 / 2 \\
0 & \sqrt{3} / 2 & -\sqrt{3} / 2 \\
1 / \sqrt{2} & 1 / \sqrt{2} & 1 / \sqrt{2}
\end{array}\right]
$$

The combination of (14) and (15) can be expressed as follows:

$$
\left\{\begin{array}{l}
L \frac{d i_{f \alpha}}{d t}=v_{s \beta}-v_{f \alpha} \\
L \frac{d i_{f \beta}}{d t}=v_{s \beta}-v_{f \beta}
\end{array}\right.
$$

In order to achieve the inverter currents tracking with respect to the reference in the next sampling time, the inverter desired output voltages in the stationary reference frame can be obtained by the discretization of (16) as follows.

$$
\left\{\begin{array}{l}
v_{\alpha f}^{*}(k)=L\left(\frac{i_{f \alpha}^{*}(k+1)-i_{f x}(k)}{T_{s}}\right)+v_{s \alpha} \\
v_{\beta f}^{*}(k)=L\left(\frac{i_{f \beta}^{*}(k+1)-i_{f x}(k)}{T_{s}}\right)+v_{s \beta}
\end{array}\right.
$$

Where $v_{\alpha x}^{*}(k)$ and $v_{\beta x}^{*}(k)$ are the predicted output voltage references respectively, and $T_{s}$ is the sampling time. Using Kirchhoff's current law at the Common Coupling Point (CCP), the following expression is obtained:

$$
i_{f x}(k)=i_{L x}(k)-i_{s x}(k)
$$

Where $i_{L x}(k)$ and $i_{s x}(k)$ are the load and supply phase currents respectively, at the sampling instant $(\mathrm{k})$. Since the sampling instant $(\mathrm{k}+1)$ is not available, $i_{f x}^{*}(k+1)$ is replaced by $i_{f x}^{*}(k)$. This introduces one sampling time delay which becomes less significant as the sampling frequency increases. The reference current of the shunt APF can be expressed as:

$$
i_{f x}^{*}(k)=i_{L x}(k)-i_{s x}^{*}(k)
$$

The substitution of (18) and (19) in (17) gives:

$$
\left\{\begin{array}{l}
v_{f \alpha}^{*}=\frac{L}{T_{s}}\left[i_{s \alpha}^{*}(k)-i_{\alpha}(k)\right]+v_{s \alpha} \\
v_{f \beta}^{*}=\frac{L}{T_{s}}\left[i_{s \beta}^{*}(k)-i_{\beta}(k)\right]+v_{s \beta}
\end{array}\right.
$$

In (20) represents the predicted inverter output voltage expressed in terms of the reference and the actual supply currents [12], [13], [23]. The main characteristic of this control strategy is the selection of the 
voltage vector that minimizes a quality function $\mathrm{g}$ [9], [23]. The quality function is expressed in orthogonal coordinates in the following form.

$$
\mathrm{g}=\left|i_{\alpha}^{*}-i_{\alpha}^{p}\right|+\left|i_{\beta}^{*}-i_{\beta}^{p}\right|
$$

Where $i_{\alpha}^{*}$ and $i_{\beta}^{*}$ are the real and imaginary parts of the future reference current. $i_{\alpha}^{p}$ and $i_{\beta}^{p}$ are the real and imaginary parts of the predicted current.

\section{SIMULATION RESULTS}

Figure 7 shows the block diagram of the shunt APF associated with a model predictive controller. Actual values of source currents $i_{s x}$ are measured at instant $\mathrm{k}$ and used as input for a predictive model that computes the values of the current at the next sampling time for each of the possible switching states of the insulated gate bipolar transistor (IGBT) inverter. These predictions are evaluated with the quality function and the vector that minimizes this function is applied during the next sampling interval. The switching state could be changed only once at each sampling instant.

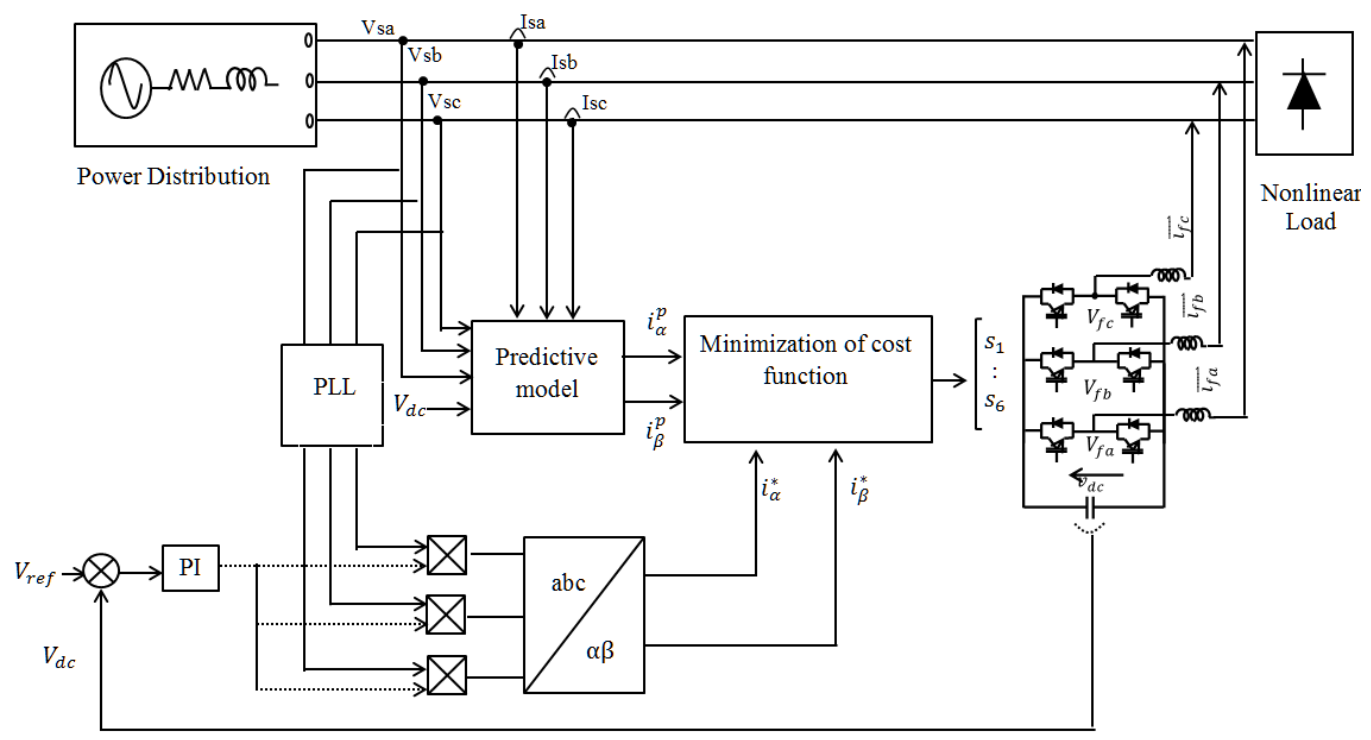

Figure 7. Shunt APF with predictive current control

In order to investigate its performance, the proposed system shown in Figure 7 is firstly evaluated by simulation using MATLAB/Simulink. The non-linear load is represented by a three-phase diode rectifier feeding an inductive load acting as a harmonic current producing source $(\mathrm{R}=50 \Omega ; \mathrm{L}=0.5 \mathrm{mH})$. The inductance of the shunt APF coupling inductor, is $3 \mathrm{mH}$. The inverter capacitor and the reference voltage are $2040 \mu \mathrm{F}$ and $173 \mathrm{~V}$ respectively. The simulation results for the system before and after compensation are shown in Figures 8, 9, 10 and 11 respectively.

The performance and the effectiveness of the shunt APF associated with predictive current control have been verified by simulation using matlab/simulink. Figure 8 shows the simulated waveforms of the source current, the load current, the filter current and the DC bus voltage before and after compensation. The results show that after compensation, the source current is nearly sinusoidal with low harmonic content which is below the harmonic limit imposed by the IEEE 519-1992 standard and the DC-bus voltage is regulated around its reference. Figure 9 shows the DC-bus voltage, the source current and the source voltage in steady state. The simulation results show that the source current and the source voltage are in phase, with a power factor nearly unity. The harmonic spectrum before connecting the APF is shown in Figure 10. The harmonic spectrum of the source current after connecting the APF is shown in Figure 11, with a good THD.

High-performance active power filter implementation based on predictive current control (Bachar Rahimap) 

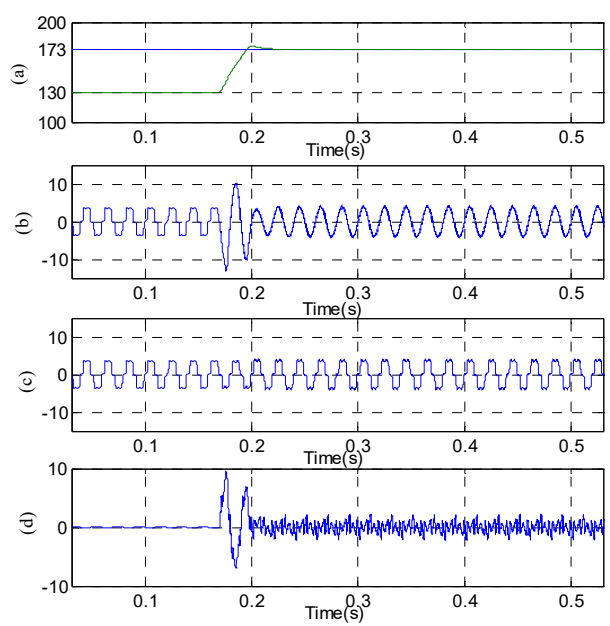

Figure 8. Simulation results: (a) DC bus voltage (V), (b) source current (A), (c) load current (A), (d) filter current (A)

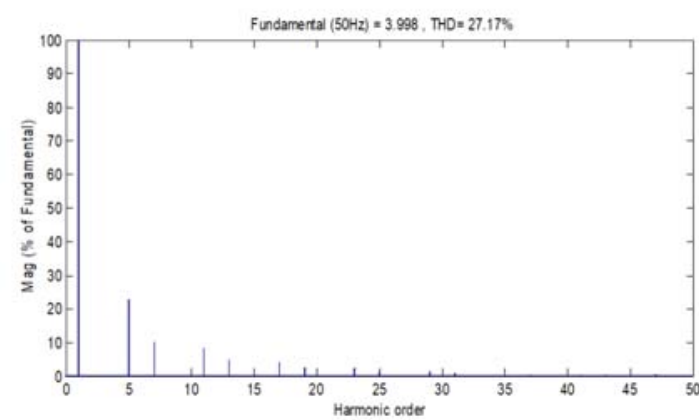

Figure 10. Harmonic spectrum before connecting the APF
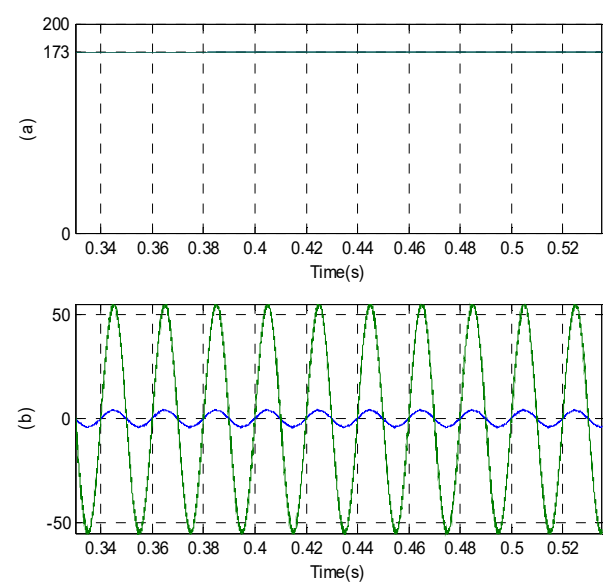

Figure 9. Simulation results: (a) DC bus voltage (V), (b) source current and voltage current

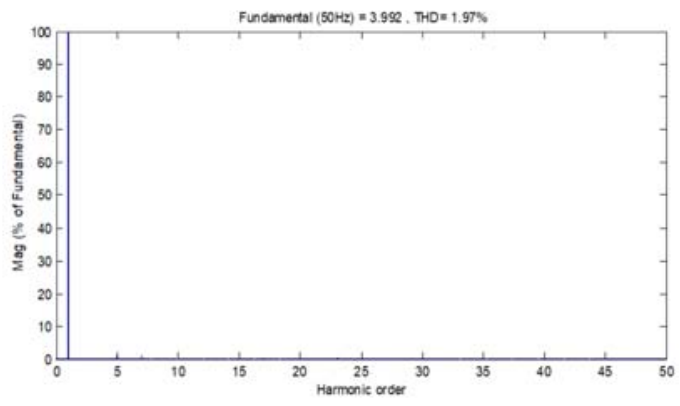

Figure 11. Harmonic spectrum after connecting the APF

\section{EXPERIMENTAL RESULTS}

The control strategy is implemented using a dSPACE card DS1104 under Matlab/SimulinkTM RTW environment. The sampling time using in practical tests is $1 \mathrm{e}-4 \mathrm{~s}$ as shown in Figure 12.

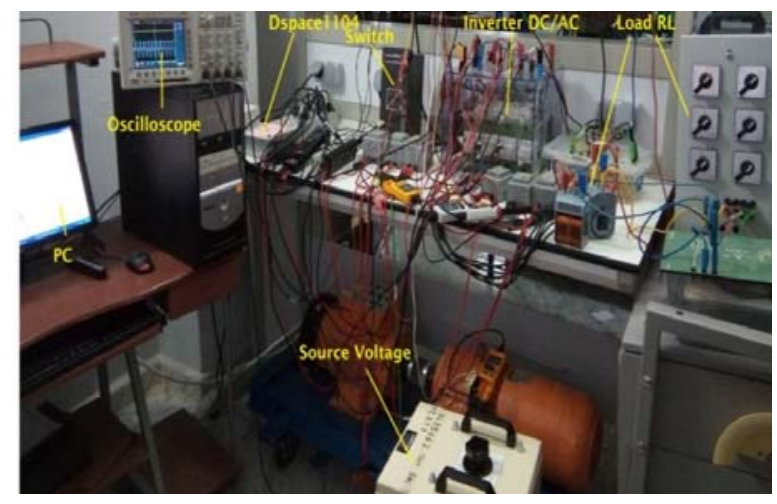

Figure 12. Experimental setup of shunt APF 
Experimental results aimed to validate the simulation results have been obtained for steady-state and transitory operation mode, as shown in Figure $13 \mathrm{a}, \mathrm{b}$ and $\mathrm{c}$.

These experimental results show the effectiveness of the APF associated with a predictive current controller, to compensate harmonic currents created by a nonlinear load and to minimize the reactive power consumption. Figure 13 (a) illustrates the dynamic responses of the source current, the load current, the injected current and the DC bus voltage. It is observed that the DC bus voltage pass through a transitional period before stabilization and reaches its reference with moderate peak voltage. After compensation, the current source is nearly sinusoidal. Figure 13(b), shows the same waveforms in steady state operation. Figure 13 (c) demonstrates that after the connection of the APF, the source current is nearly sinusoidal and in phase with the source voltage with a good power factor. Figure 14 shows the spectrum of the source current before compensation. The source current shows high harmonic content. Figure 15 illustrates the spectrum of the source current after compensation. These results demonstrate that the performance of the shunt APF based on predictive current control in terms of harmonics elimination and reactive power compensation is very satisfactory.

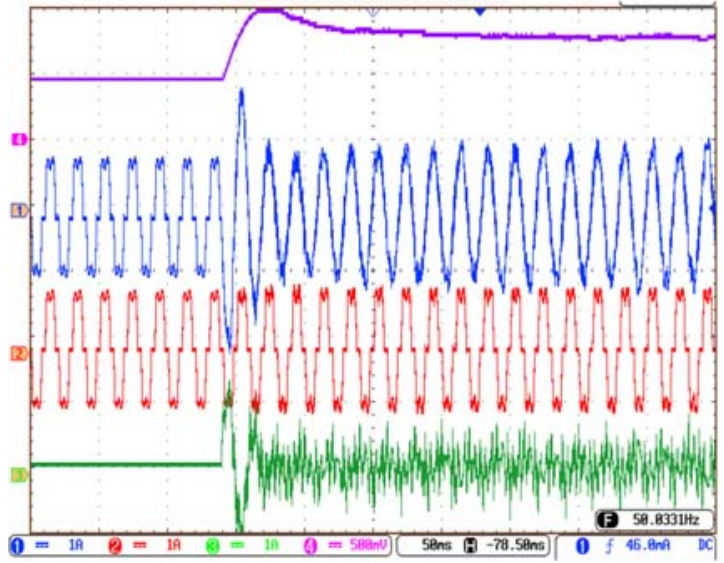

(a)Ch1, Ch2, Ch3 scale $5 \mathrm{~A} /$ div: source current $\mathrm{i}_{\text {sa }}$ (A), load current $i_{\text {La }}$, injected current $i_{\text {fa }}(A)$ respectively; Ch4 scale $150 \mathrm{~V} /$ div capacitor voltage. Time scale: $50 \mathrm{~ms} / \mathrm{div}$

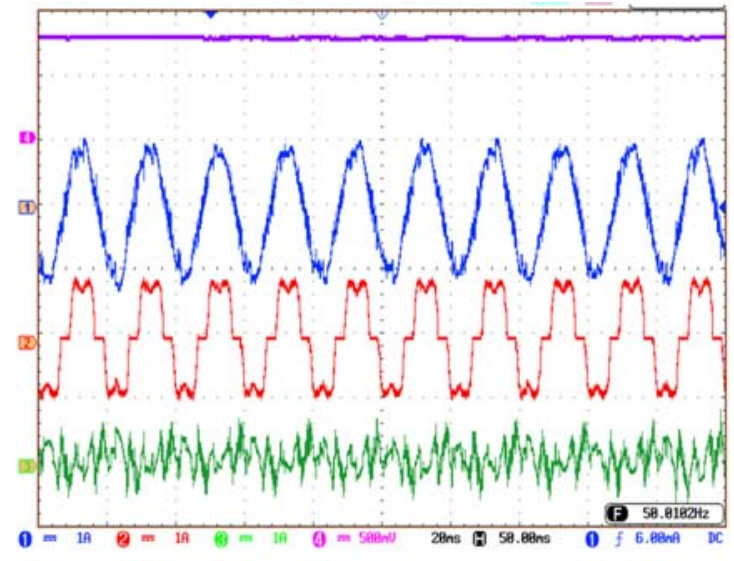

(b)Ch1, Ch2, Ch3 scale $5 \mathrm{~A} /$ div: source current $i_{s a}(\mathrm{~A})$, load currenti $i_{L a}$, injected current $i_{f a}(\mathrm{~A})$ respectively; Ch4 scale $150 \mathrm{~V} / \mathrm{div}$ capacitor voltage, Time scale: $20 \mathrm{~ms} / \mathrm{div}$

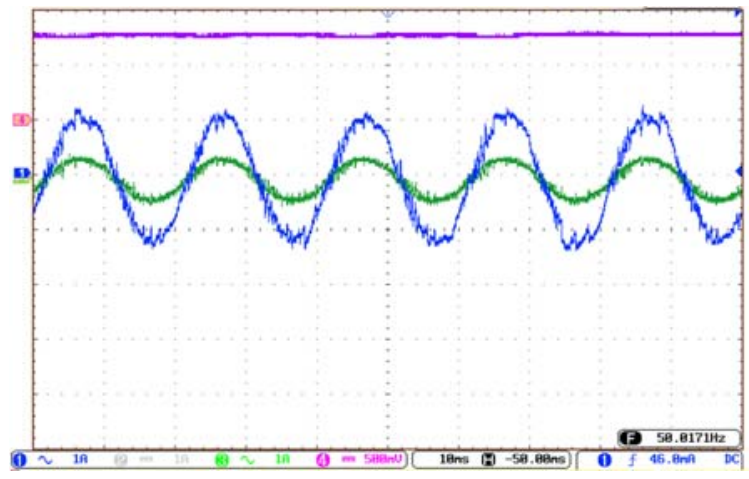

(c) Ch1 scale $30 \mathrm{~V} / \mathrm{div}$ : source voltage $v_{s a}(\mathrm{~V})$, Ch2 source current $i_{s a}(\mathrm{~A})$; Ch3 scale $150 \mathrm{~V} /$ div capacitor voltage; Time scale: $10 \mathrm{~ms} / \mathrm{div}$

Figure 13. Experimental results before and after connection of the APF 


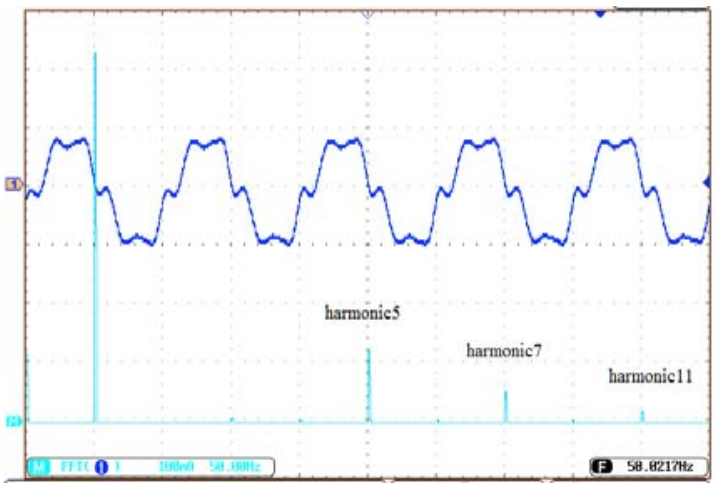

Figure 14. Harmonic spectrum before connecting the APF

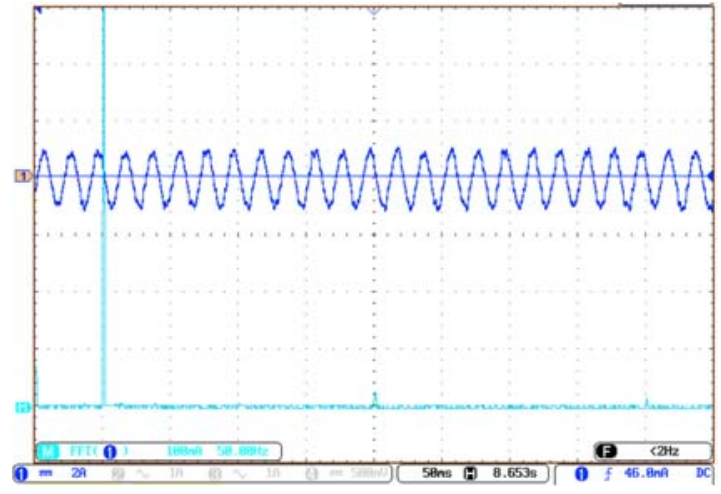

Figure 15. Harmonic spectrum after connecting the APF

\section{CONCLUSION}

In this paper the implementation of a shunt active power filter for three phase three wire system associated with a current predictive controller has been carried out. The optimal voltage vector applied to the converter is selected according to a quality function, which minimizes the error between the actuel current and the predicted one. The simulation results show the robustness and effectiveness of the proposed approach in terms of eliminating harmonics and minimizing the reactive power, with a good power factor. The THD is significantly reduced and is in conformity with the IEEE standard norms. The experimental results obtained using an experimental setup around a Dspace 1104, demonstrate the performances obtained in simulation.

\section{REFERENCES}

[1] Chennai Salim, Benchouia Mohamed Toufik, "Intelligent Controllers for Shunt Active Filter to Compensate Current Harmonics Based on SRF and SCR Control Strategies," International Journal on Electrical Engineering and Informatics, Volume 3 ,Number 3 , 2011.

[2] Chennai Salim , Benchouia Mohamed Toufik, Goléa Amar, "Harmonic Current Compensation based on Threephase Three-level Shunt Active Filter using Fuzzy Logic Current Controller," Journal of Electrical Engineering \& Technology Vol. 6, No. 5, pp. 595 604, 2011.

[3] Anup Kumar Panda and Suresh Mikkili, "FLC based shunt active filter ( $p-q$ and Id-Iq) control strategies for mitigation of harmonics with different fuzzy MFs using MATLAB and real-time digital simulator, " International Journal of Electrical Power and Energy Systems, vol. 47, pp. 313-336, 2013.

[4] Bachar Rahima, Goléa Amar, Benchouia M-T, "The Efficiency of Current Prediction Controlled Shunt Active Power Filter Based on Three Level In-verter in Balanced and Unbalanced Network Cases, " International Journal Of Engineering Science And Application Rahima Et.Al., Vol.1, No.3, 2017

[5] Nabil Elhaj, M. Brahim Sedra, Hind Djeghloud, " DFPI-based Control of the DC-bus Voltage and the AC-side Current of a Shunt Active Power Filter," Bulletin of Electrical Engineering and Informatics Vol. 5, No. 4, December 2016, pp. 430 441, DOI: 10.11591/eei.v5i4.572

[6] Ghamri A., Benchouia M.T, Golea. A , "Sliding-mode Control Based Three-phase Shunt Active Power Filter: Simulation and Experimentation, "Electric Power Components and Systems Journal , Vol. 40, No. 4, pp. 383-398, January 2012.

[7] Tarisciotti, L.Formentini, A..Gaeta, A..Degano, M..Zanchetta, P. Rabbeni, R..Pucci, M. , "Model PredictiveControl for Shunt Active Filters with Fixed Switching Frequency, " IEEE Trans. Ind. Appl. 2017, 53, 296-304.

[8] Tesfaye Alamirew, V. Balaji, Nigus Gabbeye, "Comparison of PID Controller with Model Predictive Controller for Milk Pasteurization Process, "Bulletin of Electrical Engineering and Informatics Vol. 6, No. 1, pp. 24 35, March 2017.

[9] Nan Jin , Shiyang Hu, Chun Gan , and Zhibin Ling, "Finite States Model Predictive Control for Fault-Tolerant Operation of a Three-Phase Bidirectional AC/DC Converter Under Unbalanced Grid Voltages, " IEEE Transactions On Industrial Electronics, Vol .65, No .1, January 2018.

[10] Atif Iqbal, Shaikh Moinoddin, Khaliqur Rahman, " Finite State Predictive Current and Common Mode Voltage Control of a Seven-phase Voltage Source Inverter, " International Journal of Power Electronics and Drive System (IJPEDS) Vol. 6, No. 3, pp. 459 476, September 2015.

[11] Ramon Guzmán, Luís García de Vicuña, Miguel Castilla, Jaume Miret and Antonio Camacho, "Finite Control Set Model Predictive Control for a Three-Phase Shunt Active Power Filter with a Kalman Filter-Based Estimation, " Energies 2017. 
[12] Tien Hai Nguyen and Kyeong-Hwa Kim , "Finite Control Set-Model Predictive Control with Modulation to Mitigate Harmonic Component in Output Current for a Grid-Connected Inverter under Distorted Grid Conditions, " Energies 2017.

[13] K. ANTONIEWICZ and K. RAFAL , "Model predictive current control method for four-leg three-level converter operating as shunt active power filter and grid connected inverter, "Bulletin Of The Polish Academy Of Sciences Technical Sciences, Vol. 65, No. 5, 2017.

[14] Nguyen, T.H.; Kim, K.H. , "Finite Control Set-Model Predictive Control with Modulation to Mitigate Harmonic Component in Output Current for a Grid-Connected Inverter under Distorted Grid conditions, " Energies, 10, 907, 2017.

[15] Kouro, S.Cortes, P. Vargas, R..Ammann, U. Rodriguez, J, "Model Predictive Control A Simple and Powerful Method to Control Power Converters, " IEEE Trans. Ind. Electron, 56, 1826-1838, 2009.

[16] Héctor López, Nimrod Vázquez, Juvenal Rodriguez, Eslí Vázquez, Jaime Arau, Francisco J.Perez-Pinal , "Analysis and implementation of a finite-control-set by using model solution-based control for three-phase VSI, " IET Power Electron $($ The Institution of Engineering and Technology, 2017.

[17] José Rodríguez, Jorge Pontt, César A. Silva, Pablo Correa, Pablo Lezana, Patricio Cortés, and Ulrich Ammann , "Predictive Current Control of a Voltage Source Inverter, " IEEE Transactions On Industrial Electronics, Vol. 54, No. 1, February 2007.

[18] K. Rameshkumar, A. Sakthivel, A. Senthil kumar, "Digital Predictive Current Control Strategy for Voltage Source Inverter, " International Journal of Engineering Research \& Technology (IJERT) Vol. 3 Issue 8, August - 2014.

[19] Rajesh K Patjoshi , Kamala kanta Mahapatra , "Performance Analysis of Shunt Active Power Filter using PLL based Control Algorithms Under Distorted Supply Condition, " Conference Engineering and Systems (SCES) 2013,

[20] Kishore Kumar Pedapenki, S. P. Gupta, Mukesh Kumar Pathak , "Shunt Active Power Filter with MATLAB and d'SPACE 1104 Verification," International Journal of Applied Engineering Research Volume 11, Number 6, pp 4085-4090, 2016.

[21] Fahmy, A, Hamad, M. S, Abdelsalam, A K., and Lotfy, A, "Power Quality Improvement in Three-Phase Four-Wire System using a Shunt APF with Predictive Current Control, " 978-1-4673-2421-2/12/\$31.00 @2012 IEEE.

[22] Pedro Martín Sanchez, Osmell Machado, Emilio J. Bueno Peña, Francisco J. Rodríguez, and Francisco Javier Meca , "FPGA-Based Implementation of a Predictive Current Controller for Power Converters, " IEEE Transactions On Industrial Informatics, Vol. 9, No. 3, August 2013.

[23] S. Guru Prasad, K S Srikanth, B V Rajanna, "Advanced Active Power Filter Performance for Grid Integrated Hybrid Renewable Power Generation Systems, " Indonesian Journal of Electrical Engineering and Computer Science Vol. 11, No. 1, pp. 60 73, July 2018. 